\title{
On the Mental Accounting of Restricted-Use Funds: How Gift Cards Change What People Purchase
}

\author{
NICHOLAS REINHOLTZ \\ DANIEL M. BARTELS \\ JEFFREY R. PARKER
}

\begin{abstract}
This article emphasizes the role of categorization in mental accounting and proposes that once a mental account is established, purchases that are highly congruent with the purpose of the mental account (i.e., typical category members) will be more preferred in selection decisions compared to purchases that are less congruent (i.e., atypical category members). This hypothesis is tested in the context of gift cards. Six studies find that people shopping with a retailer-specific gift card-and so, the authors argue, possessing a retailer-specific mental accountexpress an increased preference for products more typical of the retailer compared to those shopping with more fungible currency. This pattern is found to occur for both well-known retailers, where people already possess product-typicality knowledge, and fictional retailers, where product-typicality cues are provided. An alternative account based on semantic priming is not supported by these data. These results both broaden the contemporary understanding of how mental accounting influences preferences and provide retailers deeper insight into their customers' decision processes.
\end{abstract}

Keywords: mental accounting, categorization, gift cards, mental representation

Nicholas Reinholtz (nicholas.s.reinholtz@colorado.edu) is a postdoctoral research associate at the University of Colorado Boulder, Leeds School of Business, S442 UCB, Boulder, CO 80309. Daniel M. Bartels (bartels@uchicago.edu) is an assistant professor of marketing at the University of Chicago, 5807 S. Woodlawn Ave., Chicago, IL 60637. Jeffrey R. Parker (jeffparker@gsu.edu) is an assistant professor of marketing at Georgia State University, PO Box 3991, Atlanta, GA 30302. The authors thank Charlene Chen, Don Lehmann, Jonathan Levav, Malia Mason, Oleg Urminsky, Liad Weiss, Lawrence Williams, George Wu and his lab group, participants in a University of Colorado seminar, and members of hocag for their valuable comments and feedback. They also wish to thank the editor, associate editor, and three anonymous reviewers for their constructive feedback. The first author additionally thanks Dan Ariely for his generous support. An attachment to the online-only version of this article includes supplementary materials (additional experiments, analysis, and discussion). Determining order of authorship was more difficult than trying to sneak a sunrise past a gathering of roosters.

Darren Dahl served as editor, and Rebecca Hamilton served as associate editor for this article.

Advance Access publication August 27, 2015
$\mathrm{M}$ ental accounting is a framework for understanding how people label and track their money (Thaler 1985, 1999). The present work examines the role of mental accounting in product selection decisions, arguing that the formation of a mental account can predictably change preferences for one type of product over another. Specifically, purchases most congruent with the purpose of the mental account will become more preferred. Further, congruency with the mental account can be assessed using established principles of categorization and mental representation.

Our research focuses on a common situation where new mental accounts are likely to arise-the acquisition of gift cards. We argue that acquiring a gift card from a retailer (hereafter, a "retailer-specific" gift card) creates a goal to purchase from that retailer. From this premise, we build on research that argues mental accounts are formed around goals (Brendl, Markman, and Higgins 1998). Thus receiving a retail-specific gift card should trigger the intent to spend it and initiate a corresponding mental account to monitor transactions in service of this spending goal. 
Transactions that can be booked to a mental account can be treated as a category and therefore take on the attendant cognitive properties of categories (Heath and Soll 1996; Henderson and Peterson 1992). Of particular relevance to the current investigation, this category of potential transactions should possess a graded structure: category exemplars should vary in their congruence with, or representativeness of, the category concept (Medin and Schaffer 1978; Rosch et al. 1976). For example, LOW-FAT YOGURT and ROBINS are perceived to be typical members of the categories THINGS TO EAT WHILE ON A DIET and BIRDS, whereas HAMBURGERS and OSTRICHES are perceived to be atypical members of the same categories (Barsalou 1985; Hampton 1998).

The same logic applies to retailers: Some potential purchases are perceived as more representative of a retailer than others. For example, HAMBURGERs should be considered a typical member of the category THINGS TO PURCHASE FROM MCDONALD's, whereas SALADS should be considered an atypical member.

In this article, we argue that once a mental account is established, potential purchases most typical of that account (i.e., those that best satisfy the account's underlying purpose) will become more preferred compared to those that are less typical. Specifically, we measure the graded category membership of potential purchases from a retailer (i.e., their purchase typicality) and observe how preferences for these potential purchases change when a retailerspecific mental account is present (vs. absent). We predict that potential purchases more typical of the retailer (better category exemplars; e.g., hamburgers at McDonald's) should be more preferred when evaluated with respect to the retailer-specific (vs. more general) mental account.

We study this set of ideas in the domain of gift cards. Receiving a retailer-specific gift card should create a retailer-specific spending goal and mental account, whereas unrestricted gift cards (e.g., American Express gift cards) or cash should create a more general spending goal and mental account (or add to the balance of an existing mental account). We expect to observe different preferences across the same assortment of products for people possessing a retailer-specific gift card and those who do not. Possessing a retailer-specific gift card should shift preferences toward typical items (of the retailer) and away from atypical items. Six studies (plus two in the online appendix) test these predictions.

\section{MENTAL ACCOUNTING}

Standard microeconomic theories assume that potential purchases are evaluated with respect to a "comprehensive" account that includes one's overall wealth, opportunity costs, and other relevant financial considerations. Previous research, however, suggests that people instead simplify purchase decisions by evaluating prospects at a less comprehensive "topical" level (Kahneman and Tversky 1984; Soman 2004; Thaler 1980, 1985, 1999). This simplifying behavior, called mental accounting, can result in systematic and consequential deviations from microeconomic models.

Prior investigations of mental accounting tend to focus on whether a person will make a purchase or is willing to incur a new expense (Kahneman and Tversky 1984; Prelec and Loewenstein 1998). Research suggests that previous debits from a given mental account decrease a person's willingness to incur further expenses from the same account more than previous debits from other accounts. For instance, people expressed a lower likelihood of purchasing a $\$ 50$ sports ticket after purchasing a $\$ 25$ theater ticket compared to after purchasing a $\$ 25$ sweatshirt (Heath and Soll 1996). Presumably, the theater ticket purchase-but not the sweatshirt purchase-depleted the mental account to which the sports ticket expense would have been posted (e.g., an entertainment account), making the sports ticket purchase less appealing.

More recently, mental accounting research has examined the question of what people choose to purchase. This research suggests that preferences can be altered by the source of the funds included in a mental account (Arkes et al. 1994; Henderson and Peterson 1992). For example, people who receive money under negative circumstances (e.g., bequeathed by a dead relative) may prefer more pragmatic (vs. hedonic) purchases (Levav and McGraw 2009).

We build on this research and propose that receiving money elicits a goal for how that money should be spent. Constraints on received money-such as having to spend it at a specific retailer-help shape this goal and thus the purpose of the mental account used to monitor the money. Potential purchases made from the mental account can be more or less congruent with the elicited goal. For example, buying coffee should be more congruent with the goal of purchasing from Starbucks than buying an Alanis Morissette album. We argue that purchases more congruent with an established mental account will be more preferred.

\section{CATEGORIZATION AND POTENTIAL PURCHASES}

When considering how to spend funds in a newly formed mental account, potential purchases from the account can be treated as a category. In other words, people should be able to both generate items they can purchase from the mental account (i.e., list category exemplars) and evaluate whether externally provided items can be purchased from the mental account (i.e., determine category membership for novel items). This should be a noncontroversial claim, as studies suggest that even abstract ad hoc groupings (e.g., "things to take out of a burning home") take on the cognitive properties of categories (Barsalou 1983). 
The categories associated with these rich, often goal-related, concepts share several core properties with natural categories (e.g., the category of MAMMALs). Critically, both types of categories have the property of graded membership (Barsalou 1985; Lynch, Coley, and Medin 2000). This means that some category members are perceived to be better, more typical exemplars than others. For example, DOGS and HEIRLOOMS are considered to be typical members of the categories MAMMALS and THINGS TO TAKE OUT OF A BURNING HOME, whereas NARWHALS and CLOSET DOORSalthough still considered possible category members-are perceived to be more atypical (Barsalou 1985). Importantly, the graded structures of categories tend to be highly consistent across people (Mervis and Rosch 1981; Smith and Medin 1981).

Unlike natural categories, for which the graded membership of an exemplar is often a function of similarity to other category exemplars, the graded membership of an exemplar in an ad hoc category is a function of its congruence with the category's purpose or goal (Barsalou 1983; Ratneshwar and Shocker 1991). For example, items that are more valuable and portable (e.g., heirlooms) are better examples (i.e., more typical) of things to take out of a burning home than things that are less valuable and portable (e.g., closet doors) because they are more congruent with the goal that created the categorical representation.

Typicality is an important construct in the categories literature, as high-typicality exemplars of a category are cognitively privileged in a number of ways: They are (1) mentioned first in free-listing tasks (Mervis, Catlin, and Rosch 1976), (2) categorized as a member of the focal category more easily (Rips, Shoben, and Smith 1973), (3) verified as a category member more quickly (Murphy and Brownell 1985), (4) utilized more when making predictions about other category members (Rips 1975; Osherson et al. 1990), and (5) learned more quickly in category learning tasks (Rosch et al. 1976). So the typicality of category members plays a substantial role in mental representation. Mental representations (i.e., the structure of concepts stored in memory; see Alba and Hutchinson 1987, Cohen and Basu 1987, and Murphy 2002 for treatments of mental representation) are distinct from the processes that operate over these representations (i.e., encoding, accessing, and combining information from these concepts and translating it into observed responses; see Anderson 1978, Palmer 1978, and Markman 1999 for discussions of representation vs. process).

We focus on the mental representations that arise due to mental accounting and how these mental representations subsequently shape expressed preferences. We contend that a person treats retailer-specific funds (e.g., a gift card) as a mental account governed by the goal to purchase from the retailer. Potential purchases from the retailer assume the structure of an ad hoc category, which is also dependent on the goal to purchase from the retailer. Purchases that are more representative of the retailer (e.g., coffee from Starbucks) will be more typical category members. These potential purchases should be more congruent with the retailer-specific mental account and therefore should become more preferred in selection decisions once the account is established.

Henderson and Peterson (1992) presented preliminary evidence that is broadly consistent with these ideas: People behaved as if earned money should be spent differently than windfall money (cf. Arkes et al. 1994). This suggests that the source of money can change perceptions of the congruence of certain expenditures. Further, research has found that the goals that establish a given mental account can influence how the funds in that account are recorded and spent (Brendl et al. 1998). We seek to extend this research by examining more specific spending goals (i.e., to purchase from a given retailer) and by collecting and analyzing data that characterize the mental representation (i.e., category structure) of potential expenses.

Our hypothesis is about the way that restricted-use funds give rise to topical mental accounts due to the more specific spending goals they necessitate. As a case study, we examine this hypothesis in the context of retailer-issued gift cards. Whereas we would make similar predictions for other forms of currency restriction (e.g., store credit produced by returns, refunds, or coupons; business-to-business purchases made on vendor credit), as a first step, we examine how people get new funds and consequent mental accounts when they receive gift cards because gift cards are a large and growing part of the consumer landscape.

\section{GIFT CARDS, PURCHASE CONGRUENCE, AND SELECTION DECISIONS}

Gift cards are a topic of importance for marketers, both because firms like to issue gift cards and because people like to give and receive them. American retailers issue approximately $\$ 30$ billion in gift cards annually, and this number keeps growing (National Retail Federation [NRF] 2013). Gift cards have been the most popular holiday gift request every year since 2007 , more than $80 \%$ of people plan to buy at least one gift card each holiday season, and the average person planned to buy $\$ 156.86$ in gift cards for holiday gifts in 2012 (NRF 2013). People hope to receive gift cards more than any other type of gift and prefer to give gift cards as gifts because they "allow the recipient to select their own gift" (NRF 2013). As we argue below, this motivation for giving gift cards may be partially misguided.

Previous work has also linked gift cards to mental accounting (Helion and Gilovich 2014). However, no distinction was made between types of gift cards and how they could impact behavior differentially. The type of gift card (and the way it constrains possible uses) is critical to our 
hypotheses and predictions because the type of gift card should shape the underlying purpose of the mental account and the congruence of different purchases with the account.

In our studies, we use two types of gift cards: (1) retailer-specific gift cards that can only be used for purchases from the issuing retailer and (2) open-use gift cards that can be used for almost any purchase. In the retail industry, these are frequently called "closed-loop" and "open-loop" gift cards, respectively. (Note that we use "retailer" here in a broad sense indicating a company that sells a product or service to a customer. We consider restaurants, as well as golf courses, day spas, movie theaters, etc., as retailers for the present discussion.) Both types of gift cards should influence purchase decisions. Receiving any gift card might increase a person's likelihood of making some purchase for various reasons (Mu 2009; Raghubir and Srivastava 2008; White 2008). However, in the following studies, we examine another implication - that the type of gift card (i.e., retailer specific vs. open use) can influence not just whether, but what people choose to purchase.

By definition, retailer-specific gift cards are restricted in use to purchases from the issuing retailer, whereas openuse gift cards - as with cash and credit cards - are largely unrestricted in their use. To use the value of a retailerspecific gift card, a person must make an effort to purchase from the retailer. In other words, the person should adopt a retailer-specific spending goal (i.e., to purchase from the retailer), which in turn should create a retailer-specific mental account. We argue that people shopping with a retailer-specific gift card will evaluate potential purchases, in part, by their congruence with this spending goal. Congruence with the spending goal, in this case, should be a function of the categorical structure of potential purchases: purchases considered more typical of the retailer should be considered more congruent and therefore more appealing to people shopping with a retailer-specific gift card.

Open-use gift cards, in contrast, may generate mental accounts as well but ones that are more general (i.e., more comprehensive) and not associated with a specific retailer (e.g., an entertainment account). So the category of potential purchases that may be made with an open-use gift card will be less influenced by the typicality of those potential purchases with respect to any particular retailer. In our experiments, we use open-use gift cards as a control condition, as this allows us to endow participants with an equally valued gift card that should not lead to retailerlevel mental accounting.

This line of reasoning leads to the prediction that people shopping with retailer-specific gift cards, as opposed to open-use gift cards, will have a stronger preference for products typical of the retailer. Further, this pattern should reflect the graded structure of category membership: Highly typical products should increase in preference more than moderately typical products, and moderately typical products should increase in preference more than atypical products. In other words, preferences for products will be significantly affected by the type of gift card being spent, even while holding constant the choice context, monetary balance of the mental account, and characteristics of the potential expense(s).

\section{OVERVIEW OF STUDIES}

In the following studies, we manipulate whether the participant has a retailer-specific gift card or a gift card that can be used at many different retailers. In most studies, we use American Express (AmEx) gift cards-a common form of open-use gift card. Unlike retailer-specific gift cards, the value of an AmEx gift card can be redeemed anywhere that accepts traditional AmEx cards.

Studies 1 through 3 examine our hypothesis using real well-known retailers. Study 1 finds that shopping with a retailer-specific (vs. AmEx) gift card leads to stronger preferences for items perceived to be more typical of the issuing retailer. We then present an extensive pretest that determines the average perceived typicality in our experimental population for various products at different retailers. These population-level typicality measures are then used to predict the same pattern in studies 2 and 3. Also, study 3 finds a hypothesis-consistent moderating effect of brand familiarity: the relative preferences of people with low brand familiarity-those who are unlikely to know which purchases are or are not typical of the retailer-are unaffected by the type of gift card they use.

Next, studies 4 and 5 use fictional retailers (to better control for confounding factors) and examine the possible roles of conceptual priming and spreading mental activation (Stevens, Wig, and Schacter 2008). Study 4 compares shopping with a retailer-specific gift card to a control condition where we prime the brand concept. The effect of shopping with a retailer-specific gift card is replicated, whereas no effect of the priming manipulation is found. Study 5 takes a different approach-manipulating the perceived typicality of products from a hypothetical retailer. People shopping with a retailer-specific gift card are found to have stronger preferences for the items that are signaled to be more typical of the retailer (at the point of purchase) compared to people shopping with an AmEx gift card. This result is difficult to explain via conceptual priming, as there is no preexisting memory structure across which the primed activation could spread (Collins and Quillian 1969).

Finally, in study 6, we find that this pattern of results generalizes to incentive-compatible choice. Participants shopping with a retailer-specific (Levi's) gift card were more likely to purchase a typical product (jeans) than those shopping with an AmEx gift card. The article closes with a 
discussion on the implications and limitations of our investigation.

\section{STUDY 1: INDIVIDUAL-LEVEL ESTIMATES OF PURCHASE TYPICALITY PREDICT PREFERENCE DIFFERENCES}

Study 1 compared the purchase intentions of people shopping with a retailer-specific gift card to those shopping with an AmEx gift card. People shopping with retailerspecific gift cards are expected to evaluate the potential purchases, in part, by their congruence with the retailer (i.e., their purchase typicality). In contrast, those shopping with an AmEx gift card should not generate a retailerspecific spending goal or mental account and therefore should be less influenced by the congruence of purchases with the retailer. So preferences for typical products should be greater for those shopping with a retailer-specific (vs. AmEx) gift card.

\section{Method}

A total of 160 paid participants, recruited through Amazon Mechanical Turk (AMT), completed this experiment as part of a larger block of unrelated studies (we report all data exclusions in all studies). Participants were randomly assigned to one condition in a 2 (gift card: retailer-specific vs. AmEx) $\times 2$ (retailer: Levi's vs. J.Crew) between-subjects design. Gift-card type served as the primary manipulation, as this is our way of establishing a retailer-specific spending goal and corresponding mental account. The retailer manipulation allows us to examine changes in preference across the same product categories for brands with (presumably) different product-retailer associations. Note that although Levi's also sells products through third-party channels, we focus on Levi's as a retailer because they operate approximately 2,800 stores worldwide.

Participants were asked to imagine they had gone to the mall and, upon entering, unexpectedly won either a $\$ 100$ AmEx gift card or a $\$ 100$ retailer-specific gift card (either Levi's or J.Crew) for their participation in a survey. To ensure participants attended to this manipulation, they were asked to write a few sentences describing how they felt at that moment.

We then asked participants to imagine shopping at the target retailer (Levi's or J.Crew) with their gift card. Participants viewed eight product types (jeans, shirts, pants, jackets, socks, underwear, shoes, and hats), indicated the products they would consider purchasing, and then ranked their consideration set by purchase likelihood (lower numbers indicated a greater likelihood of purchase). Exact instructions are presented in the online appendix.

Next, we measured the perceived typicality of each product category relative to the target retailer. Participants answered three questions designed to measure how strongly they associated each product type with the retailer (each on a 1-9 scale). For example, a participant would be asked the following three questions for each of the eight products (Levi's and jeans are used here to illustrate): "How typical of a purchase from Levi's are jeans?" "How good of an example of a purchase from Levi's are jeans?" and "How frequently do you think people buy jeans at Levi's?" These measures were highly correlated withinparticipant (median Cronbach $\alpha=.96$ ), and so we averaged them, at the participant level, to form a purchase typicality measure (hereafter, typicality index) for each product.

\section{Results and Discussion}

We examined how each participant's relative preferences (the ranking of the items they chose to consider) were influenced by how typical they perceived each product to be of the target retailer (the typicality index). Participants in the retailer-specific (vs. AmEx) gift-card condition were expected to indicate stronger preferences for the items they viewed as more typical of the retailer.

Correlation between Typicality and Preference. We first calculated the correlation between each participant's product rankings (\#1 being the best) and the participant's typicality index for each product in the consideration set. A negative correlation indicates that the participant preferred products she viewed as more typical. As predicted, preference rankings and typicality were more negatively correlated for participants shopping with a retailer-specific gift card (mean Spearman $\rho_{\text {retailer }}=-.56$ ) than those shopping with an AmEx gift card (mean Spearman $\rho_{\mathrm{AmEx}}=-.35$, $t(141)=-2.29, p=.024$; results are stronger if Pearson correlations are used instead; 17 participants are not included in this analysis because they reported no difference in typicality of the considered products, resulting in undefined correlation coefficients).

Although the J.Crew and Levi's retailer conditions were included to test generalizability across brands, the preceding analysis is qualified by a retailer $\times$ card-type interaction when brand is included as a factor in the model: The effect of gift-card type is stronger for Levi's than for J.Crew. We report the full results in Table 1. This interaction was not predicted but makes sense and also emerges in the two studies we include in the online appendix (studies A1 and A2). In short, it seems the effect of gift-card type is constrained in the J.Crew condition by limited differentiation in purchase typicality. We further discuss this issue in the online appendix.

Additional Analysis.As a second test we analyzed the typicality of each participant's most preferred item. Participants with a retailer-specific gift card had a more typical product as their most preferred item compared to participants with an AmEx gift card $\left(M_{\text {retailer }}=7.48\right.$ vs. 
TABLE 1

STUDY 1: RESULTS BY CONDITION

\begin{tabular}{|c|c|c|c|c|}
\hline $\begin{array}{c}\text { Retailer } \\
\text { Gift-card type }\end{array}$ & Store & AmEx & Store & AmEx \\
\hline Pearson $r$ between typicality and preference & $-.78(.09)$ & $-.42(.09)$ & $-.35(.09)$ & $-.23(.09)$ \\
\hline Typicality of most preferred item & $8.31(.30)$ & $7.01(.30)$ & $6.65(.30)$ & $6.68(.31)$ \\
\hline Typicality of second most preferred item & $6.89(.34)$ & $6.80(.34)$ & $6.54(.32)$ & $6.70(.34)$ \\
\hline Typicality of third most preferred item & $5.88(.40)$ & $5.77(.41)$ & $6.07(.31)$ & $6.53(.33)$ \\
\hline Mean typicality (all products) & $4.52(.18)$ & $4.61(.18)$ & $5.41(.18)$ & $5.43(.18)$ \\
\hline Mean typicality (considered) & $6.51(.25)$ & $6.14(.25)$ & $6.19(.22)$ & $6.46(.23)$ \\
\hline Mean typicality (not considered) & $2.85(.25)$ & $3.15(.25)$ & $4.16(.28)$ & $4.12(.28)$ \\
\hline SD typicality (all products) & $2.69(.13)$ & $2.78(.13)$ & $1.71(.16)$ & $1.98(.16)$ \\
\hline
\end{tabular}

NOTE.-Correlations calculated for consideration set. Standard errors (calculated within each of the four conditions) are reported in parentheses.

$M_{\mathrm{AmEx}}=6.85, t(157)=1.98, p=.050 ;$ one participant in the AmEx-J.Crew condition put zero items in her consideration set, so she is not included in this analysis). The differences in typicality for the second and third ranked items were not significant $(|t| \mathrm{s}<.47, p \mathrm{~s}>.64)$. For the fourth ranked item, participants in the AmEx condition had a marginally more typical product than those in the retailerspecific condition $M_{\text {retailer }}=5.40$ vs. $M_{\mathrm{AmEx}}=6.17$, $t(119)=-1.81, p=.073)$.

This analysis suggests that although preference ordering seems to be a function of purchase typicality for those with a retailer-specific gift card, consideration may not be. Within the consideration set, participants with a retailerspecific gift card ranked the most typical products as most likely to be purchased. But there was no significant difference in the average typicality of considered products across gift-card conditions $\left(M_{\text {retailer }}=6.35\right.$ vs. $M_{\mathrm{AmEx}}=6.29$, $t(157)=.24, p=.81)$.

\section{PRETEST: POPULATION-LEVEL ESTIMATES OF PURCHASE TYPICALITY}

A limitation of the methodology used in study 1 is that it requires access to each person's retailer-typicality perceptions. This information is unavailable to store managers and would be impractical to collect in most cases. Also, collecting the typicality measure after the preference measure (as in study 1 ) could have biased the reported typicality ratings (e.g., via self-generated validity; Feldman and Lynch 1988). To alleviate this issue and allow the generalization of our findings to situations where individual measurements of typicality are unavailable, we conducted an extensive pretest to measure the average perceived typicality of products for a selection of retailers within our participant population. We then used these population-level measurements of typicality to predict preference changes when shopping with a retailer-specific (vs. open-use) gift
FIGURE 1

\section{TYPICALITY BY PRODUCT CATEGORY FOR LEVI'S AND J.CREW}

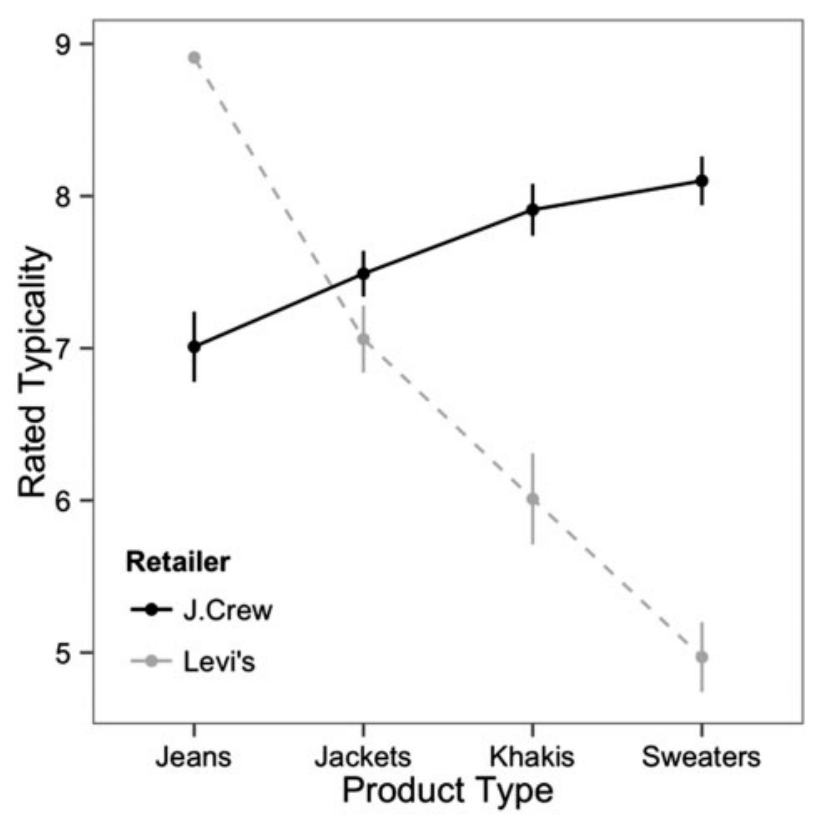

NoTE.-Error bars show between-subject standard errors.

card in studies 2 and 3. Methodological details and full results of the pretest are presented in the appendix.

This pretest yielded several pairs of retailers with contrasting purchase typicality (i.e., category) structures (see appendix). As an illustrative example, Figure 1 presents the perceived typicality for jeans, jackets, khakis, and sweaters at Levi's and J.Crew. For Levi's, jeans are perceived to be the most typical product, followed by jackets, khakis, and sweaters. For J.Crew, this pattern is reversed: 
sweaters are perceived to be the most typical product, followed by khakis, jackets, and then jeans. This product pair provides a particularly useful means for testing our central hypothesis because purchases that are typical at Levi's (e.g., jeans) are not typical at J.Crew. So our predicted result cannot be explained by changes in preference for a particular product type when shopping with a retailer-specific (vs. open-use) gift card.

\section{STUDY 2: POPULATION-LEVEL ESTIMATES OF PURCHASE TYPICALITY PREDICT PREFERENCE DIFFERENCES}

In study 2, we again manipulated whether people received a retailer-specific or an open-use gift card and whether they shopped at Levi's or J.Crew. However, instead of measuring each participant's perceptions of purchase typicality, we used the population-level measures of purchase typicality obtained in the pretest. We predicted stronger preferences for more typical purchases (e.g., jeans at Levi's) and weaker preferences for less typical purchases (e.g., sweaters at Levi's) when people were shopping with a retailer-specific gift card.

Also, study 2 included several features designed to test robustness and examine additional theories that might predict similar results: (1) Instead of assigning participants to a retailer (as we do in other studies), we allowed them to choose between shopping at Levi's and J.Crew. (2) Instead of using an AmEx for the open-use gift card (that might engender specific purchase associations), we used a gift card issued by and redeemable in a hypothetical mall where both retailers are located. Levi's and J.Crew were also described as the only apparel retailers in this mall. (3) Products were displayed with both price and quality information to control for price and quality perceptions. (4) After participants indicated their purchase preferences, we collected measures of store liking, product quality, and product hedonicity. Following these measures, we assessed the construal level of each participant. We address the potential relevance of these measures in the Results and Discussion section.

\section{Method}

A total of 797 participants, recruited through AMT, were randomly assigned to either a retailer-specific giftcard condition or an open-use ("mall") gift-card condition. Participants were asked to imagine they were planning a shopping trip to a small local mall ("the Southerland Mall") and given the choice of shopping at either Levi's or J.Crew. After selecting their preferred retailer, participants received the gift-card manipulation. Participants imagined arriving at that retailer and remembering they had recently won a $\$ 50$ gift card (either a retailer-specific gift cardLevi's or J.Crew depending on their previous choice of retailer-or a "Southerland Mall" gift card that could be redeemed at the target retailer or elsewhere in the mall) from an employee appreciation lottery at work. Participants were asked to take a few moments to think about how the situation would feel.

Participants then indicated their likelihood of purchasing each of four different product types (jeans, jackets, khakis, and sweaters) with their gift card using a constant-sum allocation measure: "Please allocate 100 points based on how likely you would be to buy from each category" $(0=$ very unlikely, $100=$ very likely $)$. To help alleviate concerns about differences in expected price or quality, each product was displayed with a common price $(\$ 50$ for each) and a roughly equal "average customer rating" (4.5 for jeans and sweaters, 4.6 for jackets, 4.4 for khakis). Additional studies, reported in the online appendix, suggest that these additional features are unnecessary to observe these results.

After indicating their purchase intentions, participants responded to a series of questions designed to examine additional influences on the predicted result. Specifically, participants answered three questions about their attitudes toward the retailer, rated the perceived quality of all four products from the retailer, and then indicated how much they perceived all four products from the retailer to be hedonic (vs. pragmatic). Finally, participants completed a scale commonly used to measure changes in construal level - the tendency to adopt either abstract or concrete representations of goal-directed actions (Behavioral Identification Form [BIF]; Vallacher and Wegner 1989; see Lee, Keller, and Sternthal 2010 for an example of the use of BIF to measure temporary changes in construal).

\section{Results and Discussion}

Predicting Preference from Typicality. Our hypothesis predicts a two-way interaction between card type and purchase typicality on purchase likelihood: Participants with a retailer-specific gift card should express a greater preference for products that are higher in retailer typicality than those with the mall (open-use) gift card. To simplify the analysis, we created a test statistic for each participant by regressing the participant's purchase intentions for each product (measured in this study) on the product's purchase typicality (measured in the pretest). We then used a $t$ test to analyze differences in the slopes of these within-subject regressions $\left(\beta_{\mathrm{i}}\right)$ that measured the expected increase in purchase likelihood for an increase in one unit of typicality.

Consistent with our hypothesis, we found that participants shopping with a retailer-specific gift card had stronger preferences for more typical products than those shopping with the mall gift card (mean $\beta_{\text {retailer }}=4.10 \mathrm{vs}$. mean $\left.\beta_{\text {mall }}=-1.15, t(795)=3.04, p=.002\right)$. In other words, possessing a retailer-specific gift card (either Levi's or J.Crew) led to greater purchase intentions for products 
TABLE 2

PREFERENCE FOR INDIVIDUAL PRODUCTS BY CARD TYPE IN STUDY 2

\begin{tabular}{|c|c|c|c|c|c|}
\hline \multirow[b]{2}{*}{ Product (Levi's) } & \multirow[b]{2}{*}{ Typicality (pretest) } & \multicolumn{4}{|c|}{ Purchase intentions } \\
\hline & & Retailer specific & Open use & Difference & $t$ \\
\hline Jeans & 8.91 & 58.3 & 52.2 & 6.11 & $2.34^{\star}$ \\
\hline Jackets & 7.06 & 17.5 & 20.6 & -3.11 & -1.59 \\
\hline Khakis & 6.01 & 11.9 & 13.7 & -1.77 & -1.10 \\
\hline Sweaters & 4.97 & 12.3 & 13.5 & -1.22 & -.82 \\
\hline \multicolumn{6}{|l|}{ Product (J.Crew) } \\
\hline Jeans & 7.01 & 28.8 & 32.3 & -3.50 & -1.38 \\
\hline Jackets & 7.49 & 27.3 & 32.3 & -5.06 & $-2.00^{\star}$ \\
\hline Khakis & 7.91 & 14.8 & 12.2 & 2.57 & 1.46 \\
\hline Sweater & 8.10 & 29.1 & 23.2 & 5.99 & $2.69^{\star *}$ \\
\hline
\end{tabular}

NOTE.-Typicality measured in pretest. For study $2, \mathrm{~N}_{\text {Levi's }}=428$ and $\mathrm{N}_{\text {J.Crew }}=369$. Asterisks indicate significant $\left({ }^{* *}: \mathrm{p}<.01,{ }^{\star}: \mathrm{p}<.05\right)$.

that were measured (a priori) to be more typical. Although this result is qualified by a significant retailer $\times$ card-type interaction, the same result emerges for Levi's (mean $\beta_{\text {retailer }}=12.04$ vs. mean $\beta_{\text {mall }}=10.18, t(426)=2.11$, $p=.036$ ) and J.Crew (mean $\beta_{\text {retailer }}=-5.14$ vs. mean $\left.\beta_{\text {mall }}=-14.25, t(367)=2.84, p=.005\right)$. This suggests that the increase in preference was not driven by product type, as the relationship between products and purchase typicality is inversed within these two retailers (i.e., jeans are most typical at Levi's and least typical at J.Crew: see Figure 1). We find this result is robust to other dependent measures (Pearson or Spearman correlation coefficients) and forms of analysis (within-subject mixed-effects regression) in the online appendix.

Analysis of Individual Products. Although our hypothesis is about the overall relationship between purchase typicality and preferences, it is also illustrative to examine the changes in relative preference for each product based on card type. As shown in Table 2, participants shopping at Levi's had stronger purchase intentions for jeans (the most typical product) when shopping with a Levi's (vs. mall) gift card, whereas purchase intentions for the other three (less typical) products decreased. For those shopping at J.Crew, purchase intentions increased for khakis and sweaters (the most typical products) when shopping with a J.Crew (vs. mall) gift card and decreased for jeans and jackets (the less typical products).

Examination of Alternative Theories. The experiments in this article were designed to test a hypothesis informed by mental accounting and the cognitive principles of categorization. Other theories, however, might potentially account for the observed results. Although we cannot exhaustively examine every possible alternative explanation of our results, we examined several of the most feasible in this study by collecting additional measures.

One possibility is that receiving a retailer-specific gift card causes participants to like the retailer more. Liking the retailer more may, in turn, lead to an increase in preference for typical products. This proposal also relies on a graded categorical representation of products offered by the retailer but does not necessitate mental accounting. To examine this proposal, we collected three measures or retailer liking after participants made their product evaluations: "How do you feel about the following retailer?" ( $1=$ "Very negative", $9=$ "Very positive"), "To what extent do you like the following retailer?" ( $1=$ "Dislike very much", 9="Like very much), and "To what extent do you prefer the following retailer over other apparel retailers in general?" ( $1=$ "Strongly prefer other retailers", $9=$ "Strongly prefer this retailer"). None of these measures were affected by the gift-card manipulation (all $|t| \mathrm{s}<.50$, all $p s>.62$ ), suggesting that receiving a retailer-specific gift card does not boost attitudes toward the retailer.

Another proposal is that receiving a retailer-specific gift card may change the perceived quality of the most typical products. Again, this would require graded category membership but not mental accounting. To assess this proposal we measured participants' perceptions of the quality for each of the four products ( $1=$ "Very low quality", $9=$ "Very high quality"). Judgments of quality did not differ significantly by gift-card type (multivariate analysis of variance [MANOVA]: $F(4,790)=.90, p=.47$ ) or the card-type $\times$ retailer interaction (MANOVA: $F(4,790)=.60, p=.66)$.

We further examined whether possessing a retailerspecific gift card may change preference for quality (i.e., that people shopping with a retailer-specific gift card might gravitate toward higher quality items). To do this we ran a within-subject mixed-effects regression model (details in the online appendix) including both a cardtype $\times$ typicality and a card-type $\times$ quality interaction. The card-type $\times$ typicality interaction remained significant $(p=.032)$; the card-type $\times$ quality interaction did not reach significance $(p=.64)$. This suggests that participants with a retailer-specific gift card were not changing their preferences based on perceived quality but rather on perceived typicality, as we predicted. 
A third possibility is that possessing a retailer-specific gift card changes a person's preference for hedonic versus pragmatic products. Helion and Gilovich (2014) suggest that possessing a gift card may increase preference for hedonic items, but they do not make a distinction between retailer-specific and open-use gift cards. To test whether gift-card type influences preference for hedonic items, we measured each participant's perceptions of the relative hedonicity of each product ("whether each product is used for mostly for practical/functional reasons $(=1)$ or pleasure/fun reasons (=9)"). Judgments of hedonicity did not differ significantly by gift-card type (MANOVA: $F(4,790)=1.66, p=.16)$ or the card-type $\times$ retailer interaction (MANOVA: $F(4,790)=.91, p=.46$ ).

To test whether participants with a retailer-specific gift card were more inclined to buy products they viewed as hedonic, we conducted a within-subject mixed-effects regression model (details in the online appendix) including both a card-type $\times$ typicality and a card-type $\times$ hedonicity interaction. Once again, the card-type $\times$ typicality interaction remained significant $\left(\beta_{\text {interaction }}=2.08, \quad t=2.68\right.$, $p=.008)$. The card-type $\times$ hedonicity interaction did not reach significance and, in fact, had a negative coefficient $\left(\beta_{\text {interaction }}=-.31, t=-.86, p=.39\right)$. Thus we found no evidence that participants were changing their preferences for more hedonic items when shopping with a retailerspecific (vs. open-use) gift card.

A final proposal implicates changes in construal level. Yao and Chen (2014) propose that people shopping with a gift card are more likely to construe information at concrete low levels compared to those shopping with cash. These authors also suggest there may be differences in construal depending on the type of gift card (e.g., mall vs. retailer specific). If low construal leads to a preference for more typical items, these changes in construal level could produce the observed pattern of results in the absence of mental accounting. To test for this, we measured whether our gift-card manipulation lead to changes in construal using the BIF (Vallacher and Wegner 1989). We did not find any differences on the BIF based on the gift-card manipulation $\left(M_{\text {retailer }}=15.14\right.$ vs. $M_{\text {mall }}=15.10, t(795)=.08$, $p=.93$ ), suggesting that changes in construal level are not causing the changes in preferences we observe. This said, we believe construal and mental accounting are related concepts, and we return to this point in the general discussion.

Conceptual Replications. Two conceptual replications are available in the online appendix. In these studies, we found that the result persists when retailers are assigned, not chosen (study A1) and when purchases are measured using Likert-type response scales instead of a constant-sum allocation (study A2). Further, we examined whether the source of the gift card moderates the effect (study A2) and found no difference between gift cards received by chance (won in a lottery) and those received from a friend. This suggests that the increased preference for typical products we see with retailer-specific gift cards is not a function of social inference (e.g., "If my friend gave me a Levi's gift card, she probably wants me to buy jeans.").

It should also be mentioned that although we find a significant positive effect of purchase typicality for people shopping with both a Levi's and a J.Crew gift card (vs. an open-use card) in study 2, we find nonsignificant effects for J.Crew in both studies A1 and A2. Instead, the effect of purchase typicality on purchase likelihood in studies A1 and A2 is confined to people shopping at Levi's. We speculate that this is because perceived differences in purchase typicality are more pronounced and consistent across people at Levi's compared to J.Crew. Because typicality is used as a predictor variable, less precise measurement impairs our ability to measure the effect in the J.Crew condition. We elaborate on and examine this idea in the online appendix.

\section{STUDY 3: GENERALIZATION TO MULTIPLE PAIRS OF RETAILERS AND MULTIPLE PRODUCT CATEGORIES}

Whereas the previous two studies have focused on a single retailer pair (Levi's and J.Crew), study 3 tests the generalizability of the results to other retailer pairs examined in the pretest. We also test a new prediction in study 3: the effect of retailer-specific (vs. open-use) gift cards on preferences should be strongest among people who are most familiar with the retailers. Previous research has found that experts have better established category representations of their domains of expertise than novices (Alba and Hutchinson 1987; Crowder 1976; Nokes, Schunn, and Chi 2010). Hence brand experts should have higher chronic availability of category structure (i.e., they should be more aware of the typicality of various products available at the retailer). In contrast, brand novices should have little knowledge of the retailer's category structure and therefore know less about the typicality of the various products sold by the retailer. So the preferences of experts should be more strongly impacted by the type of gift card (retailerspecific vs. open-use) than the preferences of novices.

Further, whereas studies 1 and 2 asked participants to rate a selection of products, each participant rated only one product for each retailer in study 3 . This change in procedure means that reference effects caused by the presence of multiple product types could not influence preferences.

\section{Method}

A total of 331 paid participants (recruited through AMT) were randomly assigned to one of 24 conditions in a 2 (gift card: retailer-specific vs. AmEx) $\times 2$ (retailer: A vs. B) $\times 2$ (product: more typical of retailer A vs. more typical of 
TABLE 3

STUDY 3: RETAILER PAIRS AND PRODUCTS

\begin{tabular}{llll}
\hline \hline Retailer A & Retailer B & $\begin{array}{c}\text { Product more } \\
\text { typical of } \\
\text { retailer A }\end{array}$ & $\begin{array}{c}\text { Product more } \\
\text { typical of } \\
\text { retailer B }\end{array}$ \\
\hline Levi's & J.Crew & Jeans & $\begin{array}{l}\text { Sweater } \\
\text { Fossil }\end{array}$ \\
Whole Foods & $\begin{array}{l}\text { Target } \\
\text { Safeway }\end{array}$ & $\begin{array}{l}\text { Watch } \\
\text { Organic produce }\end{array}$ & $\begin{array}{l}\text { Shoes } \\
\text { Frozen food }\end{array}$ \\
\hline
\end{tabular}

retailer B) $\times 3$ (retailer pairs: Levi's/J.Crew, Fossil/Target, Whole Foods/Safeway) between-subjects design (see Table 3 for a list of the retailer pairs and products used in this study). To increase the power of the study, we included a within-subject replication: After completing the procedure the first time, participants were randomly assigned to a second condition and completed the same procedure again. The within-subject replication was always in the other giftcard condition and from a different retailer pair. For example, if the participant first shopped at Levi's with a Levi's gift card, she would next shop at Fossil, Target, Whole Foods, or Safeway with an AmEx gift card.

For each replication, participants were asked to imagine they had recently received a $\$ 200$ gift card (either retailer specific or AmEx) from someone they know and to elaborate on the experience by writing a few sentences. Then they were asked to imagine themselves at the target retailer and to rate how likely they would be to purchase the target product from the target retailer on a 7 point Likert-type scale anchored by "Very unlikely" and "Very likely." After completing both replications, participants were asked to rate their familiarity with the two retailers on 7 point Likert-type scales anchored by "Not at all familiar" and "Very familiar."

\section{Results and Discussion}

We tested for the hypothesized three-way interaction between expertise, type of gift card, and product typicality (at the retailer) on purchase preference. We expected that brand experts (i.e., those with high retailer familiarity) shopping with a retailer-specific (vs. AmEx) gift card should have increased preferences for retailer-typical products (similar to what we observe in studies 1 and 2). In contrast, no differences in preferences across gift-card types were expected for brand novices (i.e., those with low retailer familiarity). We tested this prediction using a linear model with likelihood of purchase as the dependent measure and gift card (effect coded: retailer-specific $=+1$, $A m E x=-1$ ), product typicality (measured in the pretest, mean centered), and retailer familiarity (mean centered) as independent measures.

Within-Subject Replication. We first tested whether the within-subject replication biased the results using a linear regression with a fourth independent factor: whether the response was from the first or second replication (effect coded: first question $=+1$, second question $=-1$ ). The results indicated that the replication did not produce a bias: neither the four-way interaction $(t(646)=-.36, p=.72)$ nor the lower level interactions featuring the replication factor (all $|t(646)| s<1.18, p s>.18$ ) were significant. In the main results section, we control for within-subject differences with participant-level random effects (almost identical results are obtained if we instead use clustered standard errors). Results for each replication are shown in the online appendix.

Main Results. We found the predicted three-way interaction between gift-card type, product typicality, and brand familiarity $(t=2.02, p=.044$; mixed-effect analysis done using lme4 package in $\mathrm{R}$ augmented with the lmerTest package, which estimates significance of effects using Satterthwaite approximations; Bates et al. 2014; Kuznetsova, Brockhoff, and Christensen 2014). This interaction is illustrated in Figure 2.

We further explored this three-way interaction using spotlight tests (Fitzsimons 2008). Among brand experts (at +1 standard deviation [SD] from the mean on self-reported brand familiarity), we observed the predicted two-way interaction between card type and product typicality $(t=2.67, p=.008)$. As in our previous studies, shopping with a retailer-specific gift card resulted in a significantly greater likelihood of purchasing more typical products (at $+1 \mathrm{SD}$ on typicality: $M_{\text {retailer }}=5.21, M_{\mathrm{AmEx}}=4.42$, $t=2.77, p=.006$ ) and a directionally lower likelihood of purchasing less typical products (at $-1 \mathrm{SD}$ on typicality: $\left.M_{\text {retailer }}=3.10, M_{\mathrm{AmEx}}=3.41, t=-1.09, p=.28\right)$.

Among brand novices (at -1 SD on familiarity), however, there was no interaction between card type and typicality $(t=-.17, p=.87)$. This was expected because if people are unfamiliar with a retailer, they will be less able to discern typical from atypical products even if they want to purchase more typical items (as our hypothesis predicts). Instead we observed a simple main effect of card type on preference $\left(M_{\text {retailer }}=4.19, M_{\mathrm{AmEx}}=2.91, t=6.44\right.$, $p<.001)$. Although not predicted, this pattern is easily explained post hoc: brand novices with a retailer-specific gift card must purchase something at the retailer or else the value of the card would be wasted. The same people possessing unrestricted currency-an AmEx gift card-could spend that money as they choose and are less likely to spend the money on purchases from an unfamiliar brand.

In an effort to shine a "floodlight" (Spiller et al. 2013) on the three-way interaction just described, Figure 3 illustrates the regions of the parameter space where the gift card simple effect was significant. This figure conveys the same idea as shown in the spotlight analysis: for brand novices (the left side of Figure 3), possessing a retailerspecific gift card increased the likelihood of making any 
FIGURE 2

PREFERENCE FOR PRODUCTS BY CARD TYPE, TYPICALITY, AND FAMILIARITY IN STUDY 3

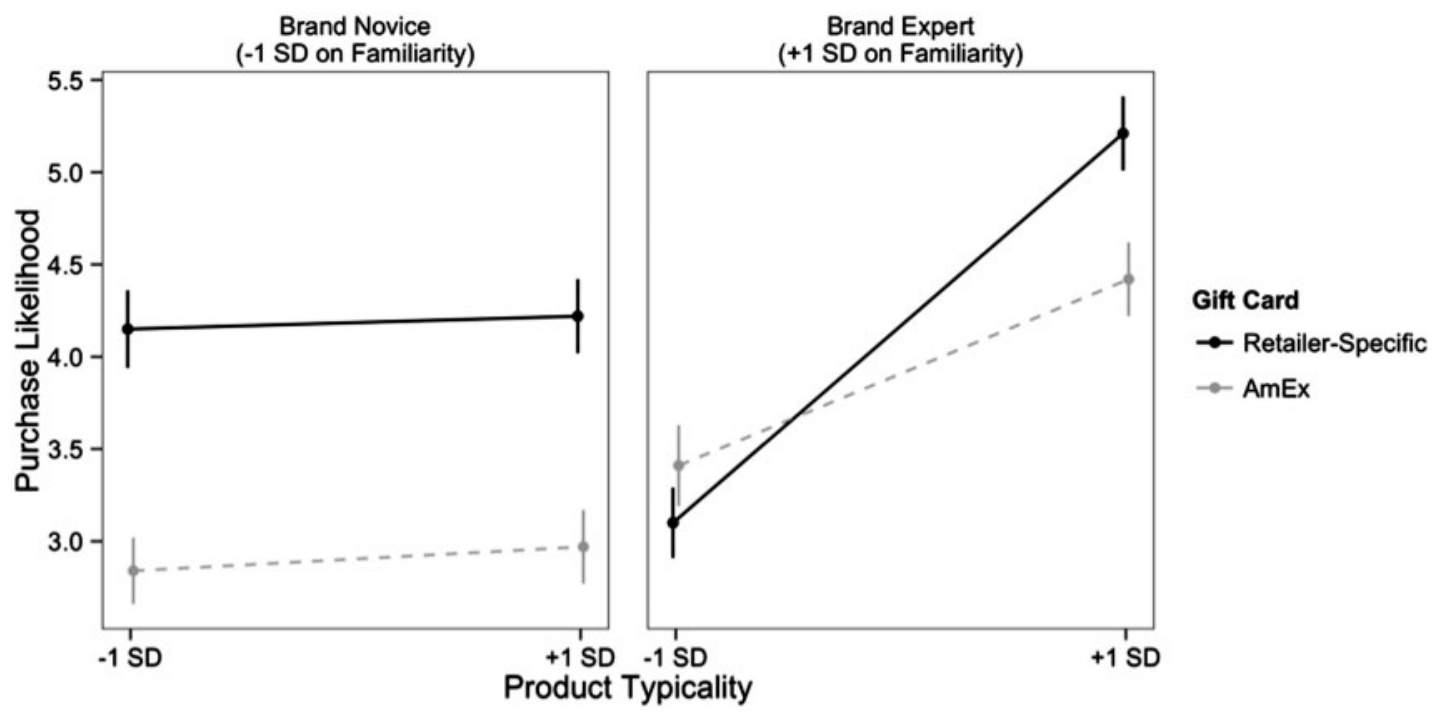

Note.-Error bars show standard errors from regression model.

FIGURE 3

PARAMETER REGIONS WHERE THE EFFECT OF GIFT CARD TYPE IS SIGNIFICANT IN STUDY 3

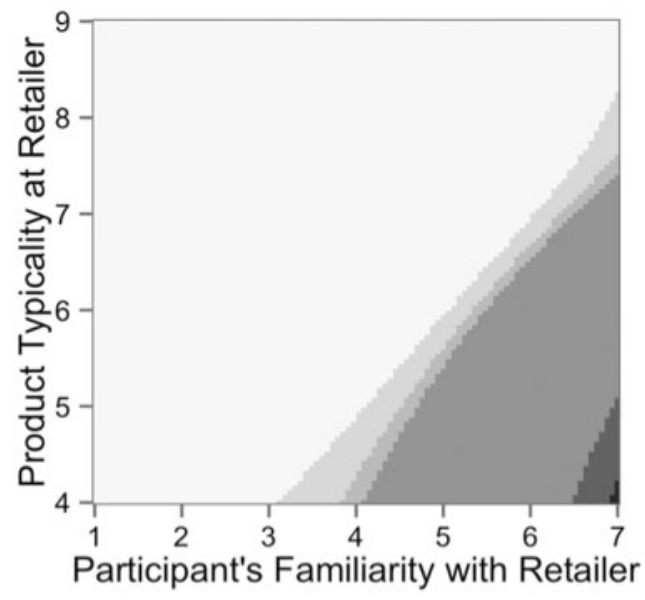

Difference in Purchase Likelihood

Higher with Retailer-Specific: $p<.01$

Higher with Retailer-Specific: $p<.05$

Higher with Retailer-Specific: $p<.10$

Not Significant

Higher with AmEx: $p<.10$

Higher with AmEx: $p<.05$

purchase. However, for brand experts (the right side of Figure 3), possessing a retailer-specific gift card had a differential effect for high- and low-typicality products. Brand experts preferred more typical products when shopping with a retailer-specific gift card (the top-right quadrant of Figure 3) and preferred less typical products when shopping with an AmEx gift card (the bottom-right quadrant of Figure 3).
A possible concern with this study is that our measure of brand familiarity ("How familiar are you with [retailer]?") could be measuring both brand expertise (our preferred explanation) and brand preference. These two constructs are related: you are more likely to know things about a brand you like. And, alternatively, you cannot like a brand that you do not know. If our measure of brand familiarity was only capturing brand preference, one could expect the 
same attenuation effect we observed. However, brand preference alone cannot explain the interaction between card type and product typicality we predicted and observed among those high in brand familiarity. Further, we also found the predicted pattern in study 2 controlling for brand liking. Although there may be some concern that brand liking is moderating the effect rather than brand expertise, it is unlikely brand liking is causing the primary result for which we find this moderation.

The studies to this point have explored preference shifts using real-world retailers. In the next two studies, we find the same result using fictional brands and examine whether our results are the by-product of simple priming effects (Anderson and Bower 1973; Stevens, Wig, and Schacter 2008), as opposed to the proposed purchase-congruence process stemming from mental accounting. A spreading activation account implies that retailer-specific gift cards prime the retailer concept and that, through spreading activation, products strongly associated with the retailer are made more accessible (Anderson 1976; McClelland and Rumelhart 1986). In turn, higher accessibility might lead strongly associated products to be more fluently processed (Whittlesea, Jacoby, and Girard 1990) and likely to be chosen (Novemsky et al. 2007).

We tested the plausibility of this account in two ways. First, in study 4, we include a condition where we prime the concept of a hypothetical brand for participants shopping with an AmEx gift card. If the priming account holds, we would expect to find no difference between this condition and the retailer-specific gift-card condition. Second, in study 5 , we signal that one of two products is typical of the hypothetical retailer at the time of choice using the label "World famous" (vs. "Today's special"). If spreading activation drives the pattern we have observed, then we should see no effect of manipulating these labels.

\section{STUDY 4: PRESUMED TYPICALITY FOR HYPOTHETICAL RETAILER}

Study 4 examined purchases made from a fictional German beer hall. Although the participants could not know what is typical of the specific beer hall in question, they should be able to recruit knowledge about what is typical of German cuisine in general to infer what might be typical of this particular beer hall. Preferences for typical German food at the beer hall should increase when participants are shopping with a retailer-specific gift card-a result that would be consistent with both the changes in mental representation we propose and the conceptual priming and spreading activation account discussed earlier.

To investigate a possible role of conceptual priming, we added a new control condition (brand-prime-AmEx) in addition to the retailer-specific and open-use gift card conditions used previously. In the brand-prime-AmEx condition, we primed the German beer hall brand concept visually. If the predicted pattern is caused by increasing the activation of the German beer hall concept in memory and increasing the activation for closely related concepts such as typical German foods (e.g., bratwurst), we should expect to see a greater preference for German foods in both the brandprime-AmEx condition and the retailer-specific gift-card condition. However, our mental accounting based hypothesis predicts an increase in preference for typical German foods only in the retailer-specific gift-card condition (where the participants would generate a retailer-specific goal and mental account) and not in the brand-primeAmEx condition.

\section{Method}

A total of 161 paid participants (recruited through AMT) completed this study as part of a larger block of surveys. We randomly assigned each participant to one of three conditions: retailer-specific gift card, AmEx gift card, or AmEx gift card with a brand prime. Participants were asked to imagine they were visiting an unfamiliar city for work and planning to have drinks with a friend the first night there. Unfortunately, the friend could not make it but left a message for the participant at the front desk of the hotel. In all conditions, the message contained an apology and a recommendation to go to the German beer hall down the street called "Der Biergarten" (a fictional restaurant). In the retailer-specific gift-card condition, the message also contained a $\$ 10$ Der Biergarten gift card (an image of which was presented to the participants). In the two AmEx gift-card conditions, the message contained a \$10 AmEx gift card (an image of which was presented to the participants). We included a Der Biergarten business card (and showed it to participants) with the AmEx gift card in the brand-prime-AmEx condition. The graphics on the Der Biergarten business card were identical to those on the Der Biergarten gift card to equate the level of supraliminal priming in the brand-prime-AmEx gift-card condition with that in the retailer-specific gift-card condition. If the pattern observed in previous studies is driven by spreading activation and not, as we argue, changes in mental accounting processes, the brand-prime-AmEx condition should yield results similar to that of the retailer-specific gift-card condition.

After receiving the gift-card manipulation, participants were asked to imagine themselves at Der Biergarten with their gift card. They were then asked to indicate their preference for four possible dishes-a chicken sandwich, a hamburger, nachos, and a bratwurst—on 9 point Likerttype scales. We predicted that participants in the retailerspecific gift-card condition would express a greater preference for the bratwurst-a product considered typical of German cuisine and therefore of Der Biergartencompared to participants in both AmEx gift-card 
conditions. Finally, participants rated how typical of German beer halls they considered the four foods on the three typicality dimensions used in study 1 and the pretest. This allowed us to test if self-reported typicality could be used to predict differences between the conditions.

\section{Results and Discussion}

Correlation between Typicality and Preference. As in previous studies, we averaged the three typicality measures to form a typicality index. This index confirmed our expectation that bratwurst was perceived to be the most typical product (see Table 4). We then used the same procedure outlined in study 1 to calculate and analyze the correlation between participants' ratings of typicality and their stated preferences. As predicted, we found a stronger correlation in the retailer-specific gift-card condition (mean Pearson $r_{\text {retailer }}=.46$ ) compared to the two AmEx conditions (mean Pearson $r_{\mathrm{AmEx}}=.23$, mean Pearson $r_{\mathrm{AmEx}+\text { prime }}=.09$; equivalent results are obtained if we instead use Spearman $\rho)$. An analysis of variance (ANOVA) revealed significant differences between the conditions $(F(2,155)=4.12$, $p=.018$; three participants, two in the AmEx condition and one in the retailer-specific condition, had undefined correlations - no variance in their preferences - and are not included in this analysis.

A planned contrast revealed the predicted result: participants shopping with a Der Biergarten gift card had preferences more strongly correlated with their perceptions of product typicality compared to those shopping with an AmEx gift card (AmEx conditions collapsed: $t(156)=2.66, p=.009)$. Further, the visual priming manipulation did not increase preferences for more typical items among those shopping with an AmEx gift card (brand prime vs. no brand prime: $t(102)=-1.03, p=.30$ ). In fact, the correlation was directionally lower for those receiving the brand prime, further suggesting that spreading activation does not explain the influence of retailer-specific gift cards on preferences.

\section{TABLE 4}

\section{PREFERENCE FOR INDIVIDUAL PRODUCTS BY CARD TYPE} IN STUDY 5

\begin{tabular}{|c|c|c|c|c|c|}
\hline \multirow[b]{2}{*}{ Product } & \multirow[b]{2}{*}{ Typicality } & \multicolumn{4}{|c|}{ Purchase intentions } \\
\hline & & $\begin{array}{l}\text { Retailer } \\
\text { specific }\end{array}$ & AmEx & $\begin{array}{c}\text { AmEx }+ \\
\text { prime }\end{array}$ & $t$ \\
\hline Bratwurst & $7.99(.12)$ & $5.75(.41)$ & $4.73(.41)$ & $4.31(.41)$ & $2.48^{\star}$ \\
\hline Hamburger & $4.82(.15)$ & $5.33(.35)$ & $4.63(.37)$ & $5.53(.33)$ & .55 \\
\hline Chicken & $3.66(.13)$ & $4.71(.34)$ & 4.49 (.37) & $4.69(.34)$ & .27 \\
\hline Nachos & $2.50(.12)$ & $3.33(.33)$ & $3.86(.36)$ & 3.29 (.33) & -.58 \\
\hline
\end{tabular}

NOTE.-Typicality measured after preferences. Between-subject standard errors shown in brackets. The $t$ statistic indicates test of retailer specific versus both AmEx conditions ( $\left.{ }^{*} \mathrm{p}<.05\right)$.
Analysis of Individual Products. We also analyzed preferences for each of the four dishes individually. An ANOVA revealed significant differences in preference for bratwurst $(F(2,158)=3.33, p=.038)$, the most typical item. A planned contrast revealed the predicted pattern $\left(M_{\text {retailer }}=5.74, M_{\mathrm{AmEx}}=4.73, M_{\mathrm{AmEx}}+\right.$ prime $\left.=4.31\right):$ participants with a retailer-specific gift card expressed a significantly greater preference for bratwurst compared to those shopping with an AmEx (AmEx conditions collapsed: $t(159)=2.48, p=.014)$. The AmEx and brandprime-AmEx conditions did not differ $(t(104)=-.72$, $p=.47$ ), again suggesting that conceptual priming and spreading activation does not explain the influence of retailer-specific gift cards on preferences. The preferences of participants for the other three dishes-chicken sandwich, hamburgers, and nachos-did not differ significantly between conditions (all $F(2,158) \mathrm{s}<1.81, p \mathrm{~s}>.16$ ). Full results are shown in Table 3 . We further probe the conceptual priming and spreading activation ideas in study 5 .

\section{STUDY 5: POINT-OF-PURCHASE SIGNALS OF TYPICALITY}

Although the previous study suggests conceptual priming and spreading activation are not responsible for the pattern we observe, a possible criticism is that our brandpriming manipulation in the control condition was insufficiently strong compared to what was primed in the retailer-specific gift-card condition (although the brandrelevant visual elements in these two conditions were identical). In study 5 , instead of relying on pre-stored typicality associations in the participant's memory, we signaled typicality at the point of purchase. In other words, participants in study 5 could not know what is typical of the hypothetical retailer before they were presented the set of options available from the retailer. So conceptual priming and spreading activation are poorly positioned to explain differences in preferences for retailer-typical products when shopping with a retailer-specific (vs. AmEx) gift card in this setting.

\section{Method}

A total of 126 paid participants (recruited through AMT) completed this study as part of a larger block of surveys. Seven participants were removed from the analysis for failing a simple attention check in an antecedent survey (although we also report the results with the seven participants included). Participants were randomly assigned to one of two between-subjects conditions (gift card: retailer-specific vs. AmEx).

Study 5, like the previous study, examined decisions in a restaurant context. However, in contrast to study 4, participants in study 5 assumed a third-person perspective to 
reduce statistical noise resulting from idiosyncratic food preferences and dietary restrictions. Participants were asked to imagine a person, Dave, dining at an Italian restaurant called Pancia Piena (a fictional restaurant) and told that Dave planned on paying for the dinner either with a Pancia Piena (retailer-specific) gift card or with an AmEx gift card. In both conditions, the gift card had been given to Dave by a friend, and the prompt noted that Dave had never been to Pancia Piena before (prompts are shown in the online appendix). Participants then saw a menu featuring five items and were asked to rank them by purchase likelihood.

Critically, we included cues on the menu to signal high typicality for one of the dishes at Pancia Piena-labeled as "World Famous" - and one of the dishes as less typicallabeled as "Today's Special" (see online appendix for stimuli). The items receiving these labels were counterbalanced. We predicted that participants who imagined Dave paying with a Pancia Piena gift card would indicate a greater purchase likelihood for the "World Famous" (vs. "Today's Special") item compared to those imagining Dave paying with an AmEx gift card.

\section{Results and Discussion}

To compare the rankings of the target menu items between conditions, we created a test statistic by subtracting each participant's ranking of the "World Famous" item from her ranking of the "Today's Special" item. (Note that this dependent measure is conceptually similar to the slope and correlation measures used in previous studies.) Higher values on this test statistic indicate a stronger preference for the "World Famous" item relative to the "Today's Special" item (e.g., if a participant rates the "World Famous" item first and the "Today's Special" item third, the test statistic for this participant would be $3-1=2$ ). Because this test statistic is not distributed normally (there can be no zero value), we compared the two conditions using a Wilcoxon rank sum test. As predicted, this test revealed that participants in the retailer-specific gift-card condition expected Dave to have a stronger relative preference for the "World Famous" (vs. "Today's Special") item $(M=.41$, median $=1)$ compared to those in the AmEx condition $(M=-.21$, median $=0 ; z=-2.11, p=.035$; if excluded participants are included: $z=-1.96, p=.050$ ).

An account based on conceptual priming and spreading activation would not predict this result. The target dishes have no links in memory to the retailer/brand (because the retailer was created for the study), so there can be no activation of the brand concept in memory that then spreads to the dishes. Differences in the strength of association between Italian food, as a general category, and each of the two dishes also cannot lead to the result because the dishes receiving the typical (vs. atypical) cue were counterbalanced.

\section{STUDY 6: INCENTIVE-COMPATIBLE PRODUCT CHOICE}

In study 6 , we return to the context of real brands but now examine incentive-compatible product choice. Like previous studies, we manipulated the type of gift card given to participants (retailer specific vs. open use). Unlike previous studies, we asked them to spend their gift card on a specific product. Further, participants' choices were consequential: after the study concluded, five participants were randomly selected to receive the product they selected. This design was used to alleviate concerns that the previously observed finding could be a result of experimental demand. If participants were compelled to select a product based on their perceptions of the research hypothesis and not based on their personal preference, they were doing so in this study against their best interest. We predicted that participants with a retailer-specific gift card would be more likely to select a typical product compared to those with an open-use gift card.

\section{Method}

A total of 236 undergraduate business students at the University of Colorado Boulder participated for course credit. Participants were randomly assigned to either shop with an open-use (AmEx) gift card or a retailer-specific (Levi's) gift card. Participants were asked to imagine they had just received a $\$ 50$ gift card (either AmEx or Levi's depending on condition) as a present and to write a few sentences about how they would feel.

Following the gift-card manipulation, participants shopped with their gift card. Participants chose whether to shop for men's or women's clothing. They then viewed and rated how likely they would be to purchase eight different products - four pairs of Levi's jeans and four Levi's sweaters-in random order on an 11 point scale $(-5=$ "Very unlikely", $+5=$ "Very likely"; products are shown in the online appendix). Each product was priced at exactly $\$ 50$ - the full value of the gift card.

After rating all of the products, participants were asked to choose one of the eight products to purchase. The instructions stressed that this choice was consequential: Five participants would be randomly selected to receive the product they selected (the preamble to the experiment also noted that they would have a chance to receive their selected product). Following the experiment, we purchased and delivered the selected products to five randomly selected participants.

\section{Results and Discussion}

The pretest found that jeans are perceived to be a more typical purchase at Levi's than sweaters. So we analyzed whether participants were more likely to select jeans from 
Levi's when shopping with a retailer-specific (Levi's) gift card compared to an open-use (AmEx) gift card. Supporting our prediction, 68\% of participants shopping with a Levi's gift card selected a pair of jeans, whereas only $51 \%$ of participants shopping with an AmEx gift card selected a pair of jeans (a logistic regression with the dependent variable dummy-coded as " 1 " for those who chose jeans and the independent variable dummy-coded "1" for those with a retailer-specific gift card: $\beta_{\text {retailer-specific }}=.73$, $z=2.69, p=.007)$. Analysis of product ratings yielded consistent, albeit weaker, results, which we detail in the online appendix.

\section{GENERAL DISCUSSION}

Over six studies (plus two in the online appendix), we found that gift cards change preferences: People shopping with a retailer-specific gift card expressed greater preferences for products they perceive to be more typical of the retailer than people shopping with more fungible currency. Study 1 found this pattern by measuring participants' preferences and their perceptions of how typical each purchase was of the target retailer (i.e., their "perceived typicality"). Participants who received a retailer-specific gift card had preferences more strongly correlated with the perceived typicality of the available products than those who received an AmEx gift card. Studies 2 and 3 found that perceived typicality measured at the population level (in the pretest) is sufficient to predict preference changes observed when people are shopping with retailer-specific gift cards. Studies 4 and 5 found the same pattern of preference changes for choices made from novel retailers signaling typicality through retailer-type associations (study 4) and point-of-purchase cues (study 5). Finally, study 6 found that these changes in preference occur for consequential choices: Participants - who had a chance to win their chosen product-were more likely to choose a pair of jeans (typical) instead of a sweater (atypical) when shopping with a Levi's (vs. AmEx) gift card.

Studies 4 and 5 cast doubt on a conceptual priming and spreading activation account of the results. Study 4 featured a priming control condition where we made the target concept (i.e., German restaurant) visually salient and found a null effect compared to the standard AmEx control condition. Study 5, alternatively, used point-of-purchase cues to signal typicality (and atypicality). Because the typicality associations provided to participants were unavailable in memory during the gift-card manipulation, priming and spreading activation are poorly positioned to explain the observed preference changes.

Also, study 2 examined and found little support for alternative explanations based on retailer liking, changes in the perceived quality of typical products, or changes in preference for hedonic products. Participants in study 2 also completed a scale that was used previously to measure temporary changes in construal level. Although we found no differences on this measure based on our manipulation (and thus no support for an influence of construal level), we wish to draw a theoretical connection here between mental accounting and construal-level theory more generally. Mental accounting involves changes in mental representation, as does construal-level theory (Day and Bartels 2008; Goodman and Malkoc 2012). Transactions can be considered in reference to general (abstract) accounts or in reference to specific (concrete) accounts. Thus a change in mental accounts can be consistent with a change in construal. This change may be localized to this decision context (and therefore not reflected in more general measures) but seems reasonable to expect in our studies. That said, it is not clear how a change in construal level would lead to our observed results. If, as Yao and Chen (2014) suggest, gift cards lead to a more concrete level of construal, without ancillary assumptions, it is not apparent why a low construal level would lead to a preference for highly typical products.

Instead, we argue the preference changes we observe are caused by the categorization processes inherent to mental accounting. When a person receives a retailer-specific gift card, or any other form of restricted-use currency, this new source of funds gives rise to a retailer-specific spending goal and consequent mental account that influences how people mentally represent potential purchases from the issuing retailer. Our key hypothesis is that once a mental account is initiated, purchases that are more congruent with the purpose of the mental account become more preferred, as they are more congruent with the spending goal underlying the account.

Our proposal that receiving a retailer-specific gift card initiates a goal to purchase from that retailer is based largely on the work of Barsalou $(1983,1991)$, who viewed the formation of goal-derived categories as a critical cognitive aspect of planning. For example, a person planning to vacation in San Francisco might form the categories of DEPARTURE TIMES THAT MINIMIZE WORK DISRUPTION, PEOPLE TO VISIT IN CALIFORNIA, and THINGS TO PACK IN A SMALL SUITCASE (Barsalou 1991). In our studies, a participant who, for example, receives a Levi's gift card must begin the process of planning how the gift card will be spent (assuming she wishes to spend it). It is in service of this intent that we propose the participant will form a goal-derived category of ITEMS I MIGHT PURCHASE FROM LEVI's. Although we are not able to provide evidence for this goal directly, we believe it is self-evident that receiving a gift card to Levi's would be more likely to engender this type of Levi's-specific planning than receiving an AmEx (or mall) gift card.

Our conclusions are related to work on consideration of opportunity costs (Bartels and Urminsky 2015; Frederick et al. 2009; Spiller 2011) and earmarking (Cheema and Soman 2011; Webb and Spiller 2014). These research 
streams examine how potential uses of money-spontaneously generated or provided-influence spending decisions. Spiller and Ariely (2014) describe a result that is particularly relevant: a person's preference for a $\$ 25$ Barnes and Noble gift card depended almost entirely on how much she valued books and e-books (typical products) and not on how much she valued music and movies (atypical products). This was true even for people who planned to use the gift card on music and movies. This can be aligned with the framework we propose: possessing a retailer-specific gift card should make typical products more attractive. Elaborating on these typical - and now more attractive products - could increase perceived value of the resource.

The results from this article have both practical and theoretical implications. On the practical side, it is important for retailers to understand how people shopping with gift cards may have different purchase motivations than people shopping with other funds. This research suggests that if retailers can predict when people will be shopping with retailer-specific gift cards, they may be able to tailor their product offerings using insights from the current studies. For example, if a person is shopping at Levi's with a Levi's gift card, or at a time of year when gift cards are more commonly used (e.g., right after the holidays), the retailer might steer this person to the store's signature line of jeans or toward clothing that features more prominent branding. Our findings also imply that higher margin, high-typicality goods might sell better at times when gift card redemption is higher.

These studies also examined implications derived from ad hoc categorization (Barsalou 1985) and related mental accounting theories (Henderson and Peterson 1992). In particular, the current studies help extend the goal-representativeness view of mental accounting (Brendl et al. 1998). We also find that - for the retailers we test, at least—brand categories, or the associations between products and brands, are similar across people. This finding is consistent with previous work on brand categories (Joiner 2007) as well as work on categorization in general (Barsalou 1985). Further, the fact that purchases made with retailer-specific gift cards were appreciably affected by the "World famous" versus "Today's special" labels in study 5 offers preliminary insight into how brand categories are formed-people readily drew inferences about purchase typicality even from these relatively subtle and easily manipulated cues.

Finally, it is worth reemphasizing that this work provides a cognitive underpinning for how preferences are formed in mental accounting. The purpose of a mental account can evoke different mental representations that, in turn, can influence consumer preferences. Our results point to some of the potentially important behavioral and economic implications of understanding how people construct and use mental representations of products and brands.
This research is not without its limitations. For instance, although we believe that our framework would hold for all restricted funds, we chose to limit our attention to gift cards for the reasons discussed. Future research might broaden the investigation to other types of constrained resources. Further, our investigation is limited to experimental studies. While this allows us to randomly assign gift-card ownership, we believe further examining these ideas in the marketplace (e.g., with panel data from a retailer) would be a valuable contribution. We hope that future researchers pursue these and other related opportunities.

\section{DATA COLLECTION INFORMATION}

The first author collected data for the pretest (fall 2011) and studies 2 (spring 2015), 3 (spring 2012), 5 (spring 2012), 6 (spring 2015), and A1 (spring 2012). The third author collected data for studies 1 (spring 2014), 4 (spring 2014), and A2 (spring 2014). All participants, with the exception of study 6, were recruited online through Amazon Mechanical Turk, and the responses were recorded using Qualtrics survey software. Participants in study 6 were recruited from the University of Colorado, and the responses were collected using Qualtrics survey software. All authors had access to these data and performed preliminary data analyses. The first author is responsible for the final analyses and interpretations presented in the article.

\section{APPENDIX: PRETEST METHOD AND RESULTS}

Six retailer pairs in six different industries were chosen using three criteria. First, we selected reasonably well-known retailers. Second, the retailers had to offer overlapping product assortments. Third, we sought retailer pairs that we suspected would have different purchase typicality associations within the identified set of products

Sixty-nine paid participants (recruited through AMT) rated all possible purchases from each retailer (e.g., jeans from Levi's) on three typicality measures. The retailer pairs, product categories, and typicality measures are presented in Table 5. Participants completed this task in blocks (one block per screen), where the participant rated the typicality of all six possible product categories for a single retailer. We randomized the order of presentation for the blocks and the order of product categories within blocks across participants.

In all, each participant responded to 216 typicality measures $(12$ retailers $\times 6$ product categories $\times 3$ typicality measures), making this a fairly arduous task. To screen for data quality, we computed a Cronbach $\alpha$ for each participant's responses across question types and removed participants whose scores were lower outliers $(\alpha$ more than $1.5 \times$ interquartile range below the first quartile; 
TABLE 5

PRETEST RESULTS

Purchase typicality measures

\begin{tabular}{|c|c|c|c|c|c|c|}
\hline \multicolumn{7}{|c|}{$\begin{array}{l}\text { How typical of a product from [retailer] are each of the following items? }(1=\text { "Not at all typical" to } 9=\text { "Very typical") } \\
\text { How good of an example of a purchase from [retailer] are each of the following items? ( } 1=\text { "Very bad example" to } 9=\text { "Very good example") } \\
\text { How frequently do you think people buy [product] at [retailer]? ( } 1 \text { ="Not frequently" to } 9=\text { "Very frequently") }\end{array}$} \\
\hline & Jeans & T-shirts & Belts & Jackets & Khakis & Sweaters \\
\hline Levi's & $8.91(.04)$ & $6.79(.18)$ & $6.19(.22)$ & $7.06(.22)$ & $6.01(.30)$ & $4.97(.23)$ \\
\hline & Organic vegetables & Vitamins & Spices & Fresh-baked goods & Cereal & Frozen food \\
\hline Whole Foods & $8.41(.19)$ & $7.12(.22)$ & $7.45(.20)$ & $6.98(.25)$ & $7.60(.17)$ & $6.51(.28)$ \\
\hline $\begin{array}{l}\text { Whole Foods } \\
\text { Safeway }\end{array}$ & $5.88(.29)$ & $6.20(.22)$ & $6.91(.22)$ & $6.98(.25)$ & $8.31(.15)$ & $8.18(.17)$ \\
\hline \multirow[t]{2}{*}{ Target } & $6.61(.22)$ & $6.92(.21)$ & $7.21(.20)$ & $7.23(.18)$ & $8.41(.11)$ & $7.40(.19)$ \\
\hline & Backpacks & Camping gear & Apparel & Water bottles & Shoes & Bicycles \\
\hline REI & $7.55(.22)$ & $7.72(.23)$ & $7.10(.21)$ & $6.67(.24)$ & $6.69(.23)$ & $6.37(.26)$ \\
\hline \multirow[t]{2}{*}{ Dick's } & $7.84(.16)$ & $8.10(.14)$ & $7.61(.14)$ & $7.18(.22)$ & $7.23(.19)$ & $7.01(.22)$ \\
\hline & Kitchen gadgets & Cleaning products & Furniture & Dorm essentials & Office supplies & Storage products \\
\hline Bed Bath \& Beyond & $7.34(.28)$ & $4.56(.31)$ & $4.64(.27)$ & $7.08(.27)$ & $4.75(.30)$ & $7.20(.24)$ \\
\hline The Container Store & $4.98(.27)$ & $3.49(.25)$ & $3.61(.24)$ & $6.48(.26)$ & $5.75(.28)$ & $8.69(.11)$ \\
\hline
\end{tabular}

NOTE.-Typicality is calculated by averaging the three measures. Means are reported with between-subject standard errors $(N=62)$ in parentheses.

Tukey 1977). This yielded 62 usable responses (median $\alpha=.89$, all $\alpha \mathrm{s}>.65$ ). To compute a typicality index, we averaged each participant's responses to the three typicality measures for each product (at the retailer level) and then averaged these scores across the sample. The purchase-typicality structure for these well-known retailers was consistent across participants (typicality index for all 72 items across 62 participants: Cronbach $\alpha=.94$ ), supporting previous arguments that brands function as categories with reliable typicality associations across people (Joiner 2007).

\section{REFERENCES}

Alba, Joseph W. and J. Wesley Hutchinson (1987), “Dimensions of Consumer Expertise," Journal of Consumer Research, 13, 411-54.

Anderson, John R. (1976), Language, Memory, and Thought, Hillsdale, NJ: Erlbaum.

- (1978), "Arguments Concerning Representations for Mental Imagery," Psychological Review, 85, 249-77.

Anderson, John R. and Gordon H. Bower (1973), Human Associative Memory, Washington, DC: V.H. Winston and Sons.

Arkes, Hal R., Cynthia A. Joyner, Mark V. Pezzo, Jane Gradwohl Nash, Karen Siegel-Jacobs, and Eric Stone (1994), “The Psychology of Windfall Gains," Organization Behavior and Human Decision Processes, 59 (3), 331-47.

Barsalou, Lawrence W. (1983), “Ad Hoc Categories," Memory and Cognition, 11 (3), 211-27.

- (1985), "Ideals, Central Tendency, and Frequency of Instantiation as Determinants of Graded Structure in
Categories," Journal of Experimental Psychology: Learning, Memory, and Cognition, 11 (4), 629-54.

_. (1991), "Deriving Categories to Achieve Goals," in The Psychology of Learning and Motivation: Advances in Research and Theory, Vol. 27, ed. Gordon H. Bower, New York: Academic Press, 1-64.

Bartels, Daniel M. and Oleg Urminsky (2015), "To Know and to Care: How Awareness and Valuation of the Future Jointly Shape Consumer Spending," Journal of Consumer Research, 41 (6), 1469-85.

Bates, Douglas, Martin Maechler, Ben Bolker and Steven Walker (2014), lme4: Linear Mixed-Effects Models Using Eigen and S4. R package version 1.1-6. http://CRAN.R-project.org/ package $=$ lme 4 .

Brendl, C. Miguel, Arthur B. Markman, and E. Tory Higgins (1998), "Mental Accounting as Self-Regulation: Representativeness to Goal-Derived Categories," Zeitschrift für Sozialpsychologie, 29, 89-104.

Cheema, Amar and Dilip Soman (2011), "Earmarking and Partitioning: Increasing Saving by Low-Income Households," Journal of Marketing Psychology, 48, 14-22.

Cohen, Joel B. and Kunal Basu (1987), "Alternative Models of Categorization: Toward a Contingent Processing Framework," Journal of Consumer Research, 13, 455-72.

Collins, Allan M. and M. Ross Quillian (1969), "Retrieval Time from Semantic Memory," Journal of Verbal Learning and Verbal Behavior, 8, 240-47.

Crowder, Robert G. (1976), Principles of Learning and Memory, Hillsdale, NJ: Erlbaum.

Day, Samuel B. and Daniel M. Bartels (2008), "Representation over Time: The Effects of Temporal Distance on Similarity," Cognition, 106, 1504-13.

Feldman, Jack M. and John G. Lynch (1988), "Self-Generated Validity and Other Effects of Measurement on Belief, 
Attitude, Intention, and Behavior," Journal of Applied Psychology, 73, 421-35.

Fitzsimons, Gavan J. (2008), "Death to Dichotomizing," Journal of Consumer Research, 35 (1), 5-8.

Frederick, Shane, Nathan Novemsky, Jing Wang, Ravi Dhar, and Stephen Nowlis (2009), "Opportunity Cost Neglect," Journal of Consumer Research, 36 (4), 553-61.

Goodman, Joseph K. and Selin A. Malkoc (2012), "Choosing Here and Now versus There and Later: The Moderating Role of Psychological Distance on Assortment Size Preferences," Journal of Consumer Research, 39 (4), 751-68.

Hampton, James A. (1998), "Similarity-Based Categorization and Fuzziness of Natural Categories," Cognition, 65, 137-65.

Heath, Chip and Jack B. Soll (1996), "Mental Budgeting and Consumer Decisions," Journal of Consumer Research, 23 (1), 40-52.

Helion, Chelsea and Thomas Gilovich (2014), "Gift Cards and Mental Accounting: Green-Lighting Hedonic Spending," Journal of Behavioral Decision Making, 27, 386-93.

Henderson, Pamela W. and Robert A. Peterson (1992), "Mental Accounting and Categorization," Organizational Behavior and Human Decision Processes, 51, 92-117.

Joiner, Christopher (2007), "Brands as Categories: Graded Structure and Its Determinants," Advances in Consumer Research, 34, 500.

Kahneman, Daniel and Amos Tversky (1984), "Choices, Values, and Frames," American Psychologist, 39, 341-50.

Kuznetsova, Alexandra, Per Bruun Brockhoff, and Rune Haubo Bojesen Christensen (2014), lmerTest: Tests in Linear Mixed Effects Models. R package version 2.0-20. http://CRAN.Rproject.org/package $=$ lmerTest.

Lee, Angela Y., Punam Anand Keller, and Brian Sternthal (2010), "Value from Regulatory Construal Fit: The Persuasive Impact of Fit between Consumer Goals and Message Concreteness," Journal of Consumer Research, 36 (5), 735-47.

Levav, Jonathan and A. Peter McGraw (2009), "Emotional Accounting: How Feelings About Money Influence Consumer Choice," Journal of Marketing Research, 46, 66-80.

Lynch, Elizabeth B., John D. Coley, and Douglas L. Medin (2000), "Tall Is Typical: Central Tendency, Ideal Dimensions, and Graded Category Structure among Tree Experts and Novices," Memory and Cognition, 28, 41-50.

Markman, Arthur B. (1999), Knowledge Representation, Mahwah, NJ: Erlbaum.

McClelland, James L. and David E. Rumelhart (1986), Parallel Distributed Processing: Explorations in the Microstructure of Cognition, Cambridge, MA: MIT Press.

Medin, Douglas L., and Marguerite M. Schaffer (1978), "Context Theory of Classification Learning," Psychological Review, 85, 207-38.

Mervis, Carolyn B., Jack Catlin, and Eleanor Rosch (1976), "Relationships among Goodness-of-Example, Category Norms, and Word Frequency," Bulletin of the Psychonomic Society, 7 (3), 283-84.

Mervis, Carolyn B. and Eleanor Rosch (1981), "Categorization of Natural Objects," Annual Review of Psychology, 32, 89-115.

Mu, Di Sabrina (2009), "Benefits and Costs of Restriction: A Comparison of Unrestricted, Restricted Gift Card Spending and Cash Spending," unpublished thesis, University of Waterloo.

Murphy, Gregory L. (2002), The Big Book of Concepts, Cambridge, MA: MIT Press.
Murphy, Gregory L. and Hiram H. Brownell (1985), "Category Differentiation in Object Recognition: Typicality Constraints on the Basic Category Advantage," Journal of Experimental Psychology: Learning, Memory, and Cognition, 11 (1), 70-84.

National Retail Federation (2013), "Monthly Consumer Survey," retrieved August 15, 2015, https://nrf.com/sites/default/files/ Gift_Cards_2013_1.pdf.

Nokes, Timothy J., Christian D. Schunn, and Michelene T. H. Chi (2010), "Problem Solving and Human Expertise," in International Encyclopedia of Education, Vol. 3, ed. Penelope Peterson, Eva Baker, and Barry McGaw, Oxford, UK: Elsevier, 265-72.

Novemsky, Nathan, Ravi Dhar, Nobert Schwarz, and Itamar Simonson (2007), "Preference Fluency in Choice," Journal of Marketing Research, 44 (3), 347-356.

Osherson, Daniel N., Edward E. Smith, Ormond Wilkie, Alejandro López, and Eldar Shafir (1990), "Category-Based Induction," Psychological Review, 97 (2), 185-200.

Palmer, Stephen E. (1978), "Fundamental Aspects of Cognitive Representation," in Cognition and Categorization, ed. Eleanor Roach and Barbara B. Lloyd, Hillsdale, NJ: Erlbaum, 259-303.

Prelec, Drazen and George Loewenstein (1998), "The Red and the Black: Mental Accounting of Savings and Debt," Marketing Science, 17 (1), 4-28.

Raghubir, Priya and Joydeep Srivastava (2008), "Monopoly Money: The Effect of Payment Coupling and Form on Spending Behavior," Journal of Experimental Psychology: Applied, 14 (3), 213-25.

Ratneshwar, S. and Allan D. Shocker (1991), "Substitution in Use and the Role of Usage Context in Product Category Structures," Journal of Consumer Research, 28, 281-95.

Rips, Lance J. (1975), "Inductive Judgments about Natural Categories," Journal of Verbal Learning and Verbal Behavior, 14 (6), 665-81.

Rips, Lance J., Edward J. Shoben, and Edward E. Smith (1973), "Semantic Distance and the Verification of Semantic Relations," Journal of Verbal Learning and Verbal Behavior, 12 (1), 1-20.

Rosch, Eleanor, Carolyn B. Mervis, Wayne D. Gray, David M. Johnson, and Penny Boyes-Braem (1976), "Basic Objects in Natural Categories," Cognitive Psychology, 8, 382-439.

Smith, Edward E. and Douglas Medin (1981), Concepts and Categories, Cambridge: Harvard University Press.

Soman, Dilip (2004), "Framing, Loss Aversion, and Mental Accounting," Blackwell Handbook of Judgment and Decision Making, ed. Derek J. Koehler and Nigel Harvey, Oxford, UK: Blackwell, 379-98.

Spiller, Stephen A. (2011), "Opportunity Cost Consideration," Journal of Consumer Research, 38 (4), 595-610.

Spiller, Stephen A. and Dan Ariely (2014), "The Perceived Value of Money Depends on Irrelevant Uses," Working Paper, UCLA.

Spiller, Stephen A., Gavan J. Fitzsimons, John G. Lynch Jr., and Gary H. McClelland (2013), "Spotlights, Floodlights, and the Magic Number Zero: Simple Effects Tests in Moderated Regression," Journal of Marketing Research, 50 (2), 277-88.

Stevens, W. Dale, Gagan S. Wig, and Daniel L. Schacter (2008), "Implicit Memory and Priming," in Learning and Memory: A Comprehensive Reference, Vol. 2, ed. Henry L. Roediger III, Oxford, UK: Elsevier, 623-44. 
Thaler, Richard H. (1980), "Towards a Positive Theory of Consumer Choice," Journal of Economic Behavior and Organization, 1, 39-60.

(1985), "Mental Accounting and Consumer Choice," Marketing Science, 4 (3), 199-214.

-. (1999), "Mental Accounting Matters," Journal of Behavioral Decision Making, 12 (3), 183-206.

Tukey, John W. (1977), Exploratory Data Analysis, Reading, MA: Addison-Wesley.

Vallacher, Robin R. and Daniel M. Wegner (1989), "Levels of Personal Agency: Individual Variation in Action Identification," Journal of Personality and Social Psychology, 57 (4), 660-71.
Webb, Elizabeth C. and Stephen A. Spiller (2014), "As Good as Spent: Earmarking Money Leads to a Psychological Sense of Spending," Working Paper, UCLA.

White, Rebecca J. (2008), "The Mental Accounting of Gift Card versus Cash Gift Funds," Advances in Consumer Research, 35,722 .

Whittlesea, Bruce W. A., Larry L. Jacoby, and Krista Girard (1990), "Illusions of Immediate Memory: Evidence of an Attributional Basis for Feelings of Familiarity and Perceptual Quality,"Journal of Memory and Language, 29, 716-32.

Yao, Qing and Rong Chen (2014), "Gift Cards and Gifted Cash: The Impact of Fit between Gift Type and Message Construal," Journal of Retailing, 90 (4), 481-92. 
Copyright of Journal of Consumer Research is the property of Oxford University Press / USA and its content may not be copied or emailed to multiple sites or posted to a listserv without the copyright holder's express written permission. However, users may print, download, or email articles for individual use. 